\title{
Sobre a possibilidade de uma pragmática histórico-crítica do sujeito em Michel Foucault
}

\author{
On the possibility of a historical-critical pragmatics \\ of the subject in Michel Foucault
}

\section{Cesar Candiotto*}

Pontifícia Universidade Católica do Paraná, Curitiba, PR, Brasil

\section{Resumo}

Neste artigo, identificamos uma modalidade específica de pragmática no pensamento de Michel Foucault, especialmente em sua arqueologia do saber dos anos 1960 e em sua genealogia dos processos de subjetivação dos anos 1980. Trata-se de uma pragmática histórico-crítica segundo a qual o sujeito jamais é algo dado, o pensamento é entendido como ação, o discurso é considerado uma prática, a história é problematizada como ficção e a liberdade é pensada como um jogo.

Palavras-chave: Crítica. Pensamento. Filosofia. Pragmática. Ética.

\section{Abstract}

In this article we identify a specific modality of pragmatics in Michel Foucault's thought. We focus especially on his archeology of knowledge, constructed in the decade of 1960, and in

*CC: Doutor em Filosofia, e-mail: ccandiotto@gmail.com 
his genealogy of the subjectivation processes in the decade of 1980. It's a historical-critical pragmatics according to which the subject is never something given, the thought is understood as an action, discourse is considered as practices, history is problematized as fiction, and liberty is thought as a game.

Keywords: Critics. Thought. Philosophy. Ethics.

\section{Introdução}

Meu propósito, neste estudo, não é exatamente tecer comparações entre a investigação de Foucault e a corrente filosófica, majoritariamente anglo-saxã, do pragmatismo - ainda que alguns de seus elementos lhes sejam convergentes ${ }^{1}-$, mas evidenciar como, desde seus primeiros trabalhos, ele tenta escapar de um modelo de filosofia ancorado em uma antropologia, ao mesmo tempo em que se aproxima de uma pragmática do sujeito.

Se é da Anthropologie de Kant que Peirce extrai o termo pragmatismo, Foucault nela encontra uma primeira inspiração para desconfiar, desde seus escritos de juventude, das antropologias filosóficas modernas. Isso é observável inicialmente na pesquisa doutoral Introduction à l'Anthropologie de Kant (1961), também conhecida como Thèse complémentaire $^{2}$. Se essa desconfiança se justifica na leitura da tese sobre Kant, ela é ainda notável nas estratégias da arqueologia do saber dos anos 1960 e na genealogia dos processos de subjetivação dos anos 1980. Na Thèse

\footnotetext{
Essa aproximação é observável principalmente com os trabalhos de William James, que também influenciaram pensadores como Bergson e Deleuze. Uma dessas aproximações é a de que a verdade não possui universalidade ou necessidade. Conforme James, "A verdade de uma ideia não é uma propriedade estagnada nessa ideia. Acontece ser a verdade uma ideia. Esta torna-se verdadeira, é feita verdadeira pelos acontecimentos (JAMES, 1974, p. 24). “A verdade é feita, do mesmo modo que a saúde, a riqueza e a força são feitas, no curso dos acontecimentos" (Ibid., p. 30). Sobre a possibilidade de uma pragmática em Foucault, convém destacar o livro Foucault, no qual Gilles Deleuze apresenta as investigações de seu amigo professor do Collège de France como uma "pragmática do múltiplo" (DELEUZE, 1986, p. 90). Já no capítulo "Foucault pragmático", da coletânea Retratos de Foucault, J. Rajchman (2000, p. 68-87) identifica um tipo original de pragmatismo nas investigações de Foucault a partir dos conceitos de problematização, artifício e prática.

2 FOUCAULT, M. Michel Foucault: Introduction à I'Anthropologie de Kant (Genèse et structure d'Anthropologie de Kant). Ed. Frédéric Gros, Daniel Defert e François Ewald. Paris: Vrin, 2008.
} 
complémentaire e no livro de 1966, Les mots et les choses, podemos conjecturar a presença de um motivo pragmático em torno do conhecimento do homem; já em diversos momentos dos anos oitenta, esse motivo é reiterado e associado à filosofia entendida como o exercício do pensamento sobre si mesmo ou ainda, como diagnóstico do presente.

Não pretendemos percorrer o conjunto da obra de Foucault para nela perscrutar minuciosamente os rastros de uma possível pragmática. Provavelmente seja um exagero apontar um motivo pragmático que permeie todo seu trabalho, embora isso não possa ser descartado. A hipótese é que essa pragmática não está limitada a uma perspectiva epistemológica, como se constata em boa parte do pragmatismo americano, ou restrita a uma apropriação ontológica, como se vê nos trabalhos Deleuze. Ela poderia ser antes delimitada como uma pragmática histórico-crítica voltada para a constituição do sujeito.

\section{0 contorno dos universais antropológicos}

Na Thèse complémentaire de 1961, traduzida ao português como Gênese e estrutura da Antropologia de Kant ${ }^{3}$, podemos identificar um conjunto de problematizações que comparecem, mais tarde, em suas investigações arqueológica e genealógica. Exemplo disso é a Notice historique, que não faz parte dessa tese, mas que acompanha a tradução francesa ao livro de Kant, editado pela Vrin, sobre a antropologia pragmática. Na última nota explicativa da Notice lemos que "As relações do pensamento crítico e da reflexão antropológica serão estudadas em uma obra ulterior" (FOUCAULT, In: KANT, 1994, p. 10). De certa maneira, essas relações podem ser encontradas já na "Introdução" a Naissance de la clinique e, posteriormente, em Les mots et les choses, embora este livro não se limite a essas relações. Em 1966, Foucault não considera da mesma maneira - ou, pelo menos, a partir da mesma comparação estrutural - o pensamento crítico e suas relações com a

3 FOUCAULT, M. Gênese e estrutura da Antropologia de Kant. Trad. Salma Tannus Muchail e Márcio Alves da Fonseca. São Paulo: Loyola, 2011. Para esse artigo, utilizaremos essa tradução. 
reflexão antropológica. Neste momento, as investigações proto-arqueológicas e arqueológicas se desdobram em uma arqueologia do saber. Os conceitos de épistémê e de a priori histórico permitem identificar o nascimento do homem na sua ambiguidade de sujeito de conhecimento e objeto de saber a partir das mesmas regras de formação histórica. A arqueologia do saber torna apreensíveis, segundo os mesmos critérios, tanto o homem tornado sujeito transcendental quanto sua constituição como objeto dos domínios empíricos da biologia, da economia política e da filologia no limiar da Modernidade.

Do ponto de vista da arqueologia do saber, o homem não passa de uma forma cuja emergência é histórica: ela nasce no final do século XIX como um acontecimento na ordem do saber. Anteriormente a essa época, nos séculos XVII e XVIII, essa forma ainda não existia, quando o homem, na condição de natureza humana, é somente uma função derivada em relação ao infinito divino. Já a partir de meados do século XX, o advento de saberes como a etnologia, a linguística e a psicanálise são sintomas de uma mudança do dispositivo do saber e indicam o provável desaparecimento do homem. Isolada a "forma" homem na regularidade dos saberes empíricos modernos da biologia, da economia política e da filologia, sua emergência como ser finito ocorre primeiro na positividade desses saberes, e não propriamente no interior da filosofia. Por sua vez, estudar essas positividades envolve compreender a emergência, o funcionamento e a transformação da figura finita do homem. Primeiro ele é "visto" residindo entre os animais, trabalhando para sobreviver e fazendo uso da linguagem; somente em um momento posterior, na qualidade de efeito, ele é assumido pelas teorias do sujeito como ser vivente, trabalhador e falante (FOUCAULT, 2000, p. 431).

Ora, a inversão do ponto de partida da arqueologia do saber em relação às filosofias do sujeito tem um motivo que não está distante de uma certa pragmática: o homem moderno não é conhecido primeiro pelo que ele é, - ou seja, um sujeito de conhecimento finito, sem ser empírico ou um sujeito constituinte e doador de sentido -, mas por aquilo que ele não é, a saber, seu envolvimento com o mundo a partir do qual a vida é ameaçada pela morte, a linguagem é desafiada pela afasia, o trabalho é acometido pelo desgaste. Antes de ser um sujeito filosófico constituinte 
do conhecimento e do mundo, o homem é constituído pelo seu envolvimento com a vida, o trabalho e a linguagem. Diante de sua compreensão como atividade sintética a priori, no sentido daquele que elabora a síntese das representações empíricas, o homem é apresentado antes como dispersão temporal entre a representação e o ser da linguagem.

Em Les mots et les choses, a identidade do homem moderno à sua consciência e ao seu pensamento é somente a dobra daquilo que lhe é anterior e subjacente na vida, no trabalho e na linguagem. A potência do trabalho, a força da vida e o poder da linguagem que condicionam o pensamento a partir de sua exterioridade permanecem irredutíveis a quaisquer definições unitárias e universais do homem como sujeito constituinte. Pelo contrário, ele é constantemente perseguido por aquilo que o limita e o condiciona, tais como o desgaste, a doença e a morte. Nesse sentido, as descrições arqueológicas podem ser consideradas uma espécie de antropologia às avessas. A partir delas, a unidade do sujeito se desagrega, o pensamento se dispersa e a consciência é condicionada pelo não-ser.

Temos, pois, uma nítida relação entre Les mots et les choses e a Introduction à l'Anthropologie de Kant, com a diferença de que no livro de 1966 a relação entre o pensamento crítico e a antropologia se desdobra em uma investigação propriamente arqueológica, consoante a qual a tentativa de uma sincronia histórica de domínios positivos de saber, contemporâneos entre si, é conjugada à descontinuidade diacrônica de cada um desses domínios. Pela arqueologia do saber, Foucault indica a provisoriedade da forma "homem" na sua frágil constituição de sujeito de conhecimento e objeto para uma ciência possível.

\section{0 pensamento é ação e exercício}

Um motivo pragmático encontrado em Les mots et les choses, mas também em boa parte de suas arqueologias e genealogias, parte da seguinte problemática: como é possível filosofar sem apoiar-se em um universal antropológico ou em um sujeito, considerado fonte de conhecimento e doador de sentido? Ou ainda, como será possível o 
pensamento sem postular como seu fundamento o sujeito da filosofia e das ciências humanas?

Desde o momento em que o pensamento se encontra acossado pelo impensado e pelos seus envolvimentos com o mundo, Foucault considera que uma metafísica é impossível, assim como qualquer moral. De onde a imperatividade de passar do aspecto prático para o pragmático: empreender a aventura de pensar a partir de um vazio, sem um sujeito puro prático, sem a consciência doadora de sentido. Nesse momento é que a filosofia deixa-se envolver pelo pensamento. Ela não pode continuar a existir como antes, ao modo de um sistema fechado ou de um corpus explicativo, à medida que doravante ela se encontra "disseminada em uma grande quantidade de atividades diversas" (FOUCAULT, 2001, p. 625). Antes de, apressadamente, pensar que a arqueologia do saber postula o fim da filosofia, seria mais prudente cogitar que esta descreve sua metamorfose. Como enfatiza Guillaume Le Blanc: "A filosofia se desdobrou, ela se aloja doravante nas atividades dos linguistas, dos historiadores, dos etnólogos, dos juristas, em pensamentos de campos diferentes. Ela é o nome que designa atos múltiplos de pensamento" (LE BLANC, 2006, p. 3). Desde que deixa de ser somente uma elaboração sistemática, totalizadora, centrada no sujeito e passa a dirigir-se ao pensamento, a filosofia se compromete também com outros domínios que transcendem a teoria.

Para o pensamento moderno, não há moral possível; pois, desde o século XIX, o pensamento já 'saiu' de si mesmo em seu ser próprio, não é mais teoria; desde que ele pensa, fere ou reconcilia, aproxima ou afasta, rompe, dissocia, ata ou reata, não pode impedir-se de liberar e de submeter. Antes mesmo de prescrever, de esforçar um futuro, de dizer o que é preciso fazer, antes mesmo de exortar ou somente alertar, o pensamento, ao nível de sua existência, desde sua forma mais matinal, é, em si mesmo, uma ação - um ato perigoso (FOUCAULT, 2000, p. 453).

Após o ocaso do reino da metafísica - pelo menos a que corresponde ao declínio da representação clássica no final do século XVIII - , depois da crise das filosofias do sujeito - pelo menos daquelas em que o empírico se confunde com o transcendental na época moderna - , a 
filosofia se envolve com pensamentos heterogêneos e imersos em uma finitude instável e precária. O pensamento deixa de ser a expressão de um sujeito constituinte, sendo doravante condicionado pela ação.

Alguns sinais dessa metamorfose da filosofia na empresa teórica de Foucault dão mostras de sua importância, principalmente em algumas passagens de seus ditos e escritos dos anos oitenta. Um primeiro pode ser identificado por ocasião da redação da primeira versão da introdução ao segundo volume de sua Histoire de la sexualité, parte dela dedicada a uma apresentação retrospectiva de seu trabalho. Essa parte não foi publicada como Introdução, mas retrabalhada, ligeiramente modificada e incluída no verbete "Foucault", para o Dictionnaire des philosophes, de Denis Huisman, publicado em 1984. Nesse texto, Foucault lê retrospectivamente sua trajetória como uma "História crítica do pensamento" (Cf. FOUCAULT, 2001, p. 1450-1455). Embora nele reconheça que seu trabalho se inscreve na tradição crítica aberta por Kant, não se trata de fazer uma crítica da razão filosófica, no sentido de uma razão fechada em si mesma, mas de abrir a atitude crítica na direção de focos de pensamento não-filosóficos. Ou ainda, a crítica deixa de inscrever-se somente no interior da própria filosofia, desde o momento em que ela é considerada um modo específico de pensamento que pode ser questionado por outros domínios de pensamento e, inclusive, reorientado por eles (LE BLANC, 2006, p. 4).

Outro sinal do encaminhamento da filosofia em direção do pensamento não-filosófico e que nos leva a reafirmar a presença de um motivo pragmático nos trabalhos de Foucault é evidenciado na "Introdução" de Histoire de la sexualité, II: l'usage des plaisirs (1984). Reescrita diversas vezes, essa introdução indica a tentativa de delimitação dos volumes II e III da Histoire de la sexualité e das "modificações" de seu projeto original. Todavia, ela também é o retrato de como Foucault lê o conjunto de sua pesquisa naquele momento. Se somos tentados à identificar um "testamento filosófico" nas últimas palavras públicas pronunciadas no curso Le courage de la vérité e em seus estudos sobre os últimos momentos da morte de Sócrates (GROS apud FOUCAULT, 2009, p. 314), a "Introdução" poderia ser pensada como o "testamento escrito" de seu 
trabalho, voltado à problematização da sexualidade e, de maneira extensiva, à maneira como ele procura fazer sua filosofia.

Nessa Introdução, a filosofia é designada como o "trabalho crítico do pensamento sobre si mesmo" (FOUCAULT, 1984, p. 16). Foucault adverte que suas investigações são estudos de "história" pelos campos que tratam, mas que não são trabalhos de "historiador". Significa que não se procura sair da filosofia para encontrar em outros domínios a atividade do pensamento. $\mathrm{O}$ nascimento das ciências humanas e sociais não corresponde ao fim da filosofia, mas à necessidade de sua transformação. Na sequência do texto, é destacado, a modo de apositivo, que esses estudos, "se quisermos encará-los do ponto de vista de sua pragmática" (FOUCAULT, 1984, p. 16) constituem o protocolo de um exercício peculiar: o exercício filosófico. O modo investigativo de Foucault, portanto, é situado de um ponto de vista pragmático sempre que ele percorre diferentes domínios do exercício do pensamento. E esse exercício é crítico, porque os limites que podem ser postos a cada um desses domínios não são efetuados a partir deles mesmos, mas pela sua interação com outros domínios do saber. Nesse sentido é que a história crítica do pensamento, quando trata dos domínios empíricos, afasta-se de uma teoria geral da ciência; ou, sempre que estuda conteúdos filosóficos, toma distância de uma teoria do sujeito de conhecimento.

\section{Pensamento e ascética}

A metamorfose da filosofia em direção do exercício crítico do pensamento sobre si mesmo, assim como o lugar que lhe é atribuído na pluralidade das práticas em diferentes domínios do saber e sua mútua interação têm ressonâncias éticas e políticas.

Nas antropologias, o pensamento é o elemento originário de onde parte não somente a verdade, mas também a unidade e a universalidade do sujeito. Em contrapartida, na arqueologia do saber e na genealogia das práticas de subjetivação, o pensamento deixa de ser considerado o procedimento inato de uma faculdade; ele passa a ser 
designado como o exercício de separação de si mesmo, o descaminho que envolve "pensar diferentemente do que se pensa" e "perceber diferentemente do que se vê" (FOUCAULT, 1984, p. 17) ${ }^{4}$.

O pensamento tem uma caracterização pragmática. É apresentado de maneira operante ao modo de exercício permanente. Quando pensamos sempre a mesma coisa, não estamos, à rigor, exercitando o pensamento. Por sua vez, desde que renunciamos a pensar - e, posto que o pensamento é um modo de ação - na verdade deixamos de agir e, com isso, somente seguimos regras, e encontramo-nos presos às cadeias da obediência excessiva e burocrática.

Na condição de exercício crítico do pensamento, a filosofia adquire importância na genealogia dos processos de subjetivação dos anos oitenta em um domínio específico de práticas, que são as práticas de si, dentre elas, as práticas ascéticas. Segue a importância do redirecionamento do projeto inicial da Histoire de la sexualité nessa época: não se deter somente no cristianismo dos primeiros séculos ${ }^{5}$, mas problematizar as práticas de si no Império romano tardio e no mundo grego clássico. O cristianismo criou o ascetismo, mas foram os gregos e romanos que inventaram a ascética. No interior da vida monástica cristã o ascetismo visa a renúncia do eu, o apagamento da vontade própria e a obediência integral, dando origem a uma moral da obediência. Já a ascética grega e romana busca a transformação do sujeito, a estilística da liberdade e o senhorio de si mesmo no âmbito de uma estética da existência.

Ascese, em grego Askesis, significa literalmente "exercício". No ascetismo cristão dos primeiros séculos esse exercício demanda a verbalização infinita para que o mal pensamento seja expulso, assim como a obrigação da obediência integral para colocar em prática somente

4 Deleuze entende que pensar remete a um lado de fora que não tem forma, algo não-estratificado. "Ver é pensar, falar é pensar, mas o pensar opera no interstício, na disjunção entre ver e falar". Diferentemente de Kant, pensar não é o exercício inato de uma faculdade, mas "deve suceder ao pensamento", desmembra o vivível e 0 enunciável, abre as palavras e as coisas sem nunca coincidirem (DELEUZE, 1986, p. 93).

5 Foucault realiza sua análise da conduta sexual nas práticas de si cristãs, do século ll a $\mathrm{V}$ d.C., no livro Histoire de la sexualité: Les aveux de la chair (2018), no qual foram acrescentados três anexos pelo editor, Frédéric Gros. Muitas das temáticas ali presentes podem ser lidas em paralelo com o curso de 1980 no Collège de France, Du gouvernement des vivants (publicado em 2012), principalmente os estudos sobre a exomologese e a exagorese. Esse curso, porém, está orientado pela relação entre 0 governo da alma e a manifestação da verdade. 
aquele pensamento que provém de Deus. Não estamos efetivamente diante de um exercício do pensamento sobre si mesmo, posto que se trata sempre de examinar a qualidade do pensamento que provém de alguém outro, do Maligno ou de Deus. Além disso, esse exercício exige sempre um outro que escuta, interpreta e exige obediência. No ascetismo, não está em questão o exercício do pensamento como também o conteúdo daquilo que se pensa, mas sua origem, sua marca, sua raiz, o que ele esconde e o que ele revela. Depreende-se uma hermenêtica do pensamento e uma renúncia a pensar somente a partir de si mesmo.

Em contrapartida, na ascética identificada entre gregos e romanos, encontramos o exercício do pensamento sobre si mesmo, posto que se busca justamente se desfazer de preconceitos sedimentados, de visões de mundo pré-concebidas, de estilos de ser e viver cristalizados e que fazem parte da maneira de pensar o mundo e as relações humanas.

Cogitamos que esse interesse de Foucault pela ascética greco-romana tem relação com a designação pragmática de filosofia, como exercício do pensamento. Por certo, as práticas científicas, sociais e culturais nas quais nos encontramos nos levaram a pensar somente aquilo que deve ser pensado, a ver somente aquilo que é circunscrito a um campo de visibilidade, a nomear somente aquilo que é delimitado em um campo de enunciabilidade. Em contrapartida, a filosofia como exercício pragmático do pensamento busca ver diferentemente aquilo que se tornou naturalizado ao nosso olhar, alterar a maneira de perceber as práticas que nos concernem no cotidiano e criar um estilo de existência próprio diante das regras que nos são postas pela cultura. Ela é ascética pois envolve o exercício de transformação de quem pensa e daquilo que é pensado, do sujeito e do objeto, a partir da multiplicidade das práticas científicas, sociais e de subjetivação.

\section{0 discurso como prática}

O deslocamento foucaultiano da filosofia rumo ao pensamento e a compreensão deste último como ação e exercício demandam percorrer o conceito plural de "práticas". Se a prática, no sentido singular, 
corresponde quase sempre a um campo próprio de um sujeito determinado a partir do qual o pensamento se dobra diante da filosofia, já as práticas e sua racionalidade designam um campo sem um sujeito definido, no qual muitos sujeitos poderão ser constituídos.

As práticas em sua multiplicidade e heterogeneidade podem ser apresentadas como outra possibilidade da caracterização da pragmática histórico-crítica do pensamento. Elas podem ser identificadas ainda às formações históricas sobre as quais se debruçam as arqueologias e genealogias. E, desde logo, elas são inalcançáveis pela mera interpretação ou comentário. Desde o prefácio a Naissance de la clinique, entende-se que no visível e no enunciável não há um significado, ao mesmo tempo, revelado e escondido (Cf. FOUCAULT, 1997, p. XII). O grande princípio histórico de Foucault, enfatiza Deleuze, é o de que "toda formação histórica diz tudo o que pode dizer, e vê tudo o que pode ver" (DELEUZE, 1992, p. 121). Seu peculiar pragmatismo se afasta de qualquer perspectiva hermenêutica. Mais do que serem interpretadas, as formações históricas são consideradas em sua materialidade de experimentação.

E para Foucault experimentar é problematizar algo que se torna motivo de preocupação. Como ressalta na entrevista Le souci de la vérité, concedida a François Ewald em maio de 1984, no Magazine littéraire, e retomada nos Dits et écrits:

Problematização não significa a representação de um objeto preexistente, nem tampouco a criação pelo discurso de um objeto que ainda não existe. Trata-se do conjunto das práticas discursivas ou não discursivas que permite a alguma coisa ingressar no jogo do verdadeiro e do falso e o constitui como objeto para o pensamento (seja sob a forma da reflexão moral, do conhecimento científico, da análise política, etc.) (FOUCAULT, 2001, p. 1489).

Portanto, problematizar significa situar-se no campo das práticas entre as quais algo pode se tornar um objeto para o saber. Como exemplifica Foucault, nessa mesma entrevista, em referência à loucura: 
Na Histoire de la folie, a questão consistia em saber como e por que a loucura, em um dado momento, foi problematizada através de uma certa prática institucional e um determinado aparelho de conhecimento. [...] Mas agregarei logo que, no caso da loucura, tentei reunir a partir dela a constituição da experiência de si mesmo como louco, no quadro da doença mental, da prática psiquiátrica e da instituição asilar (FOUCAULT, 2001, p. 1488-1489).

Foucault não deduz as práticas das instituições, das teorias ou das ideologias (cf. FOUCAULT, 2001, p. 841). Até certo ponto, as práticas têm sua regularidade própria, sua estratégia, sua técnica, enfim sua razão de ser. Inexistem práticas mudas pois elas sempre carregam consigo um regime de racionalidade. Elas são o lugar do encadeamento do que se diz e do que se faz. Os discursos, em sua materialidade, são designados como "práticas que formam sistematicamente os objetos dos quais eles falam" (FOUCAULT, 1969, p. 66-67). As arqueologias e genealogias procuram definir "os discursos como práticas que obedecem a regras" (Ibid., p. 182). Essas regras, convém lembrar, se depreendem da épistémê de cada época ou do dispositivo do saber-poder de cada formação histórica.

Das práticas heterogêneas e múltiplas de cada camada histórica é que são deduzidos os processos de objetivação, assim como os processos de subjetivação. Em boa parte de seus estudos dos anos sessenta e setenta, por exemplo, sua preocupação é saber o que "se fazia" (FOUCAULT, 2001, p. 1454) com o louco e o doente, com o delinquente e o incorrigível para que eles fossem objetivados e se reconhecessem como sujeitos da loucura, da doença e do crime. Trata-se da ênfase nas práticas divisórias constituídas por racionalidades e dispositivos que cindem os seres humanos no interior de si mesmos e no âmbito das relações sociais, entre normais e anormais.

Se estudei 'práticas' como aquelas do sequestro dos loucos, da medicina clínica, da organização das ciências empíricas ou da punição legal, era para estudar esse jogo entre um 'código' que regra maneiras de fazer (que prescreve como dividir as pessoas, como examiná-las, como classificar as coisas e os signos, como adestrar os indivíduos etc.) e uma produção de discursos verdadeiros que serve de fundamento, justificação, razões 
de ser e princípio de transformação dessas mesmas maneiras de fazer. Para dizer as coisas claramente: meu problema é saber como os homens se governam (eles mesmos e os outros) por meio da produção de verdade (repito ainda, por produção de verdade: não entendo a produção de enunciados verdadeiros, mas a disposição de domínios em que a prática do verdadeiro e do falso pode ser ao mesmo tempo regrada e pertinente) (FOUCAULT, 2001, p. 845-846).

Exercitar o pensamento em torno dessas práticas de objetivação e subjetivação tem como efeito não nos deixar indiferentes em relação àquilo que fizeram de nós, com as separações e cesuras históricas que constituem o que ainda somos. Essa não indiferença impulsiona um "fazer-se" contínuo, não como dever universal, mas como possibilidade contingente. A depender do contato dos indivíduos com as estratégias de poder, com a regularidade dos saberes ou com as práticas históricas que os condicionam, eles não são conduzidos ao aprendizado de uma doutrina, mas à possibilidade de uma transformação na sua maneira de pensar e agir.

Se a ênfase em livros como Histoire de la folie, Surveiller et punir, La volonté de savoir e Les aveux de la chair recai sobre daquilo que fizeram de nós, já nos livros L'usage des plaisirs e Le souci de soi pergunta-se sobre o que pode fazer o sujeito de si mesmo quando se toma como objeto de um saber possível, de uma relação coercitiva ou de uma condução da conduta determinada?

Diante do que "fizeram de nós" nas práticas de objetivação e sujeição, adquire importância capital a noção de atitude crítica: sem entrar em maiores detalhes sobre sua origem ou seus diversos significados, limito-me a enunciar a sugestão indicada em Le gouvernement des vivants, segundo a qual seu vigor se concentra na atitude de questionamento, tanto da verdade do poder quanto do poder da verdade (FOUCAULT, 2012, p. 98-99) como gesto filosófico por excelência. Pela grade de inteligibilidade da atitude crítica, são diagnosticadas as verdades constituídas para legitimar o exercício do poder e suas práticas divisórias entre normais e anormais, assim como é posto a nu o poder constringente da verdade que nos obriga a assumir uma identidade determinada. E a partir desse diagnóstico, surge a pergunta inevitável: 
o que podemos "fazer de nós mesmos" para que nos tornemos sujeitos de nossas práticas, de nossas ações? Kant, no seu artigo sobre a Aufklärung, pergunta "Quem somos nós, hoje"? Foucault, por sua vez, põe à prova essa questão na heterogeneidade e na multiplicidade das práticas históricas. Suas pesquisas delas fazem uso, deslocando-as para a análise de canteiros históricos que envolvem diferentes processos de constituição do sujeito.

\section{A história como ficção}

Diante da pergunta kantiana a respeito do que podemos e devemos fazer de nós mesmos em relação às práticas históricas e culturais entre as quais somos marcados com uma identidade, Foucault aposta na elaboração de ficções históricas cujos artifícios anteriores a quaisquer determinações universais objetivam desgarrarmo-nos daquilo que somos (ou fizeram de nós).

As histórias arqueológicas e genealógicas são ficcionais porque quem as escreve e aqueles que as lê é impelido a fabricar a si mesmo e a transformar sua relação consigo, com os outros e com o mundo. À medida que essas ficções ajudam a questionar as evidências de nossa cultura e nossa história, isto é, aquilo que é possível "nomear, falar e pensar" em uma determinada época (FOUCAULT, 2000, p. XVI); e, a partir do momento em que essas ficções auxiliam a nos desprender da imagem objetivada pela qual fomos levados a reconhecer nossa identidade, elas se afastam de qualquer associação entre essa identidade e uma suposta verdade a ela indexada.

Uma pragmática histórico-crítica do sujeito não se detém nos comportamentos, ideias e sociedades, mas na problematização de diferentes domínios a partir dos quais o ser humano se dá como "podendo e devendo ser pensado" (FOUCAULT, 1984, p. 15). Nesse sentido, a problematização da doença, da loucura, da criminalidade e da sexualidade no momento presente é estudada a partir de suas descontinuidades com as práticas históricas do passado (ou do arquivo) a fim de 
propor um retorno, não em vista da atualização do passado, mas da invenção de novas maneiras de ser e viver no presente.

Toni Negri chama a atenção para essa "máquina estranha" de Michel Foucault conforme a qual a história é pensada "somente como história do presente". Consoante o pensador italiano, o fundamental em Foucault é seu método "pois lhe permite estudar e descrever o movimento entre passado e presente; e entre presente e futuro. É o método da transição cujo centro é o presente. Foucault está ali no meio, não entre o passado e o futuro, mas ali naquele presente que os distingue. É ali que se instala o questionamento" (NEGRI, 2016, p. 15-16). Portanto, o princípio de método é a problematização histórico-filosófica, o meio é o arquivo das práticas do passado e a finalidade é o diagnóstico do presente. Seu efeito é a possibilidade de invenção do atual, ou seja, aquilo que Deleuze nomeia como nosso "devir-Outro" (DELEUZE, 1988, p. 191).

Se o percurso pelos arquivos empoeirados e de pouca glória de nosso passado recente objetiva indicar o que fizeram de nós, já a tarefa filosófica do diagnóstico do presente supõe apontar até que ponto aquilo com o qual nos identificamos, poderia deixar de sê-lo. Como salienta Foucault na entrevista Structuralisme et Poststructuralisme, de 1983, sobre a função do diagnóstico:

[...] ela não consiste simplesmente em caracterizar o que somos, mas, segundo as linhas de fragilidade atuais, chegar a compreender por onde aquilo que é e como aquilo que é poderia não mais ser o que é. E é nesse sentido que a descrição deve sempre ser feita segundo esta espécie de fratura virtual, que abre um espaço de liberdade, entendido como espaço de liberdade concreto, ou seja, de transformação possível (FOUCAULT, 2001, p. 1267-1268).

A suposição dessa fratura virtual é que possibilita a relação das ficções com o diagnóstico do presente. As ficções históricas podem ser lidas como experiências que mudam, que nos impedem de ser sempre os mesmos ou obliteram as relações que tínhamos com os objetos, antes de conhecê-los. Elas proporcionam uma ruptura das evidências nas quais se apoiam nossos saberes, consensos e práticas e promovem, desse modo, o surgimento de novos processos de subjetivação. 
O motivo pragmático fundamental encontrado nas ficções históricas é que elas permitem pensar o sujeito não como um universal antropológico, mas como uma espécie de plasticidade a ser modulada historicamente, seja pela sua objetivação nas práticas sociais, seja pela sua subjetivação nas práticas de si. Há sempre um artifício possível na região da experimentação que provoca um estranhamento em relação às objetivações efetuadas e sujeições consentidas e, além disso, desembaralha seus mecanismos e apresenta sua frágil constituição.

\section{Uma pragmática da liberdade}

O diagnóstico do presente se relaciona com a ficção abrindo-se assim para a liberdade, entendida enquanto liberdade concreta ${ }^{6}$. Em uma entrevista de janeiro de 1984 e publicada postumamente, a ética é designada como "prática refletida da liberdade" (FOUCAULT, 2001, p. 1530).

Quando tratamos da dimensão ética da liberdade na Modernidade, é quase natural pensamos no terceiro desdobramento do Imperativo Categórico de Kant, do livro Fundamentação da metafísica dos costumes. Todavia, na genealogia das práticas de subjetivação, a liberdade não se identifica com esse conceito de autonomia derivado de uma liberdade transcendental e elevada ao estatuto de legislação moral universal. Pelo contrário, ela sempre é considerada uma prática, no sentido de exercício e jogo. Prática que, quando refletida, é portadora de certa racionalidade e atua na estruturação ética do sujeito. O sujeito se constitui como alguém livre somente quando age livremente, diante de uma tentativa de condução de sua conduta. São considerados livres os "sujeitos individuais ou coletivos que têm diante de si um campo de possibilidade no qual diversas condutas, diversas reações e diversos modos de comportamento podem ter lugar (FOUCAULT, 2001, p. 1056).

6 Podemos dizer que há uma compreensão do homem e da liberdade como efeitos da aplicação de tecnologias do eu nos dispositivos de poder, mas há também seu entendimento a partir de um exercício, de uma ascética pensada a partir das técnicas de si. 
Essas passagens nos lembram a atenção concedida por Foucault ao Prefácio da Introduction à l'anthropologie d'un point de vue pragmatique, em sua Thèse complémentaire. Na perspectiva de Kant, a condição da antropologia pragmática é que o homem seja tomado, não a partir daquilo que a natureza fez dele, mas como ele, enquanto ser de "livre atividade", pode e deve fazer de si mesmo (KANT, 1994, p. 11). Pragmaticamente entendido, o homem se faz, se fabrica por meio da luta contínua entre o poder e o dever, entre a possibilidade e a obrigação de alcançar um modo de ser específico e nele permanecer.

Na Thèse complementaire, o moi deixa de ser considerado em seu estatuto de objeto para ser compreendido como liberdade em exercício. E a região do "exercício humano" é aquela na qual o sujeito é pensado em termos de sua constituição. Talvez pudéssemos afirmar que nos trabalhos de Foucault - inspirando-se em Kant, porém assumindo uma lateralidade em relação a ele - o sujeito não é somente aquilo que as práticas científicas e sociais de objetivação historicamente fizeram dele, mas principalmente aquilo que ele pode e deve fazer de si mesmo diante da relação com estas práticas. Desse modo é que pode ser entendida uma passagem da aula de 5 de janeiro de 1983, do curso Le gouvernement de soi et des autres. Foucault apresenta o que poderia ser chamado de "pragmática de si" como o terceiro "foco de experiência" de seu trabalho, dedicado à "constituição do modo de ser do sujeito". Não se trata, nesse caso, de fazer uma história da subjetividade ou uma teoria do sujeito, mas de "analisar essas formas de subjetivação mediante as técnicas/tecnologias da relação consigo" (FOUCAULT, 2008, p. 6-7).

Não existe relação de poder sem ações livre e, nesse sentido, podemos também dizer que a liberdade assume um modo concreto, a depender da técnica de poder que se aplica sobre ela. Da mesma maneira, na estruturação ética do sujeito, analisada, por exemplo, nos volumes 2 e 3 da Histoire de la sexualité, livre deixa de ser o adjetivo do indivíduo que é estatutariamente assim reconhecido, mas antes é atribuído àquele que consegue estabelecer um bom uso de sua liberdade na luta contra seus próprios desejos. Foucault desloca a problemática do poder para uma dimensão agonística, conforme a qual a oposição beligerante dos antagonismos políticos dá lugar à provocação incessante entre "a 
insistência do querer e a intransitividade da liberdade" (FOUCAULT, 2001, p. 1057). A liberdade tem um sentido pragmático porque não é inerente ao sujeito e jamais permanece a mesma. Ela assume uma forma concreta, a depender das tecnologias de poder que a provocam e a produzem, ou das técnicas de si que estimulam seu exercício, diante das forças do querer que tentam determiná-la inteiramente.

\section{Considerações finais}

Como vimos, o surgimento da figura do homem como objeto de saber e sujeito de conhecimento na arqueologia do saber é deduzido de sua finitude e da exterioridade de suas determinações. Nesse conjunto, quaisquer verdades que lhe são atribuídas são reportadas antes às regularidades, descontinuidades e multiplicidades operantes na análise arqueológica dos saberes. Já nos processos de subjetivação dos anos oitenta, o homem deixa de ser objetivado somente nas práticas discursivas; antes, ele se fabrica, se ficciona e se constitui livremente como objeto para si próprio no intuito de se transformar em sujeito ético em cada foco de experiência no qual ele se encontra envolvido.

A arqueologia das práticas científicas, desenvolvida em Les mots et les choses, privilegia a relação entre os saberes, contrapondo-se às diferentes tentativas das ciências do homem de lhe delimitar uma verdade ou afastando-se da ideia de um sujeito constituinte deduzido dos desdobramentos da antropologia filosófica. A genealogia dos processos de subjetivação, por seu turno, destaca as diferentes modalidades da relação do indivíduo consigo mesmo, diante da ideia do sujeito moral das antropologias, oriunda dos códigos morais e suas proibições. No entanto, esses privilégios e destaques não envolvem a negação das ciências humanas e das teorias morais. Em relação a esses domínios do saber, Foucault empreende uma crítica. Ela aponta a insuficiência do plano teórico de cada um desses discursos quando eles partem da unidade e da universalidade do sujeito e prescindem de sua constituição histórica.

Um dos aspectos mais marcantes das análises de Foucault consiste na determinação das condições históricas de possibilidade desses 
universais antropológicos nas ciências humanas e na filosofia moral a fim de contorná-los e, portanto, relativizá-los. Esse recorte permite concluir que estamos diante de uma pragmática histórico-crítica pela qual o sujeito jamais é um universal antropológico, o pensamento é sempre ação e permanente exercício, as práticas enlaçam o que se diz e o que se faz, a histórica é problematizada como ficção e a liberdade é pensada como jogo.

\section{Referências}

DELEUZE, G. Foucault. Paris: Les editions de Minuit, 1986.

DELEUZE, G. Qu'est-ce qu'un dispositif? In: CANGUILHEM, G. (Org.). Michel Foucault philosophe. Rencontre Internationale. Paris: Seuil, 1988. p. 185-195.

DELEUZE, G. A vida como obra de arte. In: Conversações: 1972-1990. Trad. bras. Peter Pál Pelbart. Rio de Janeiro: Editora 34, 1992. p. 118-126.

FOUCAULT, M. Notice historique. In: KANT, E. Anthropologie du point de vue pragmatique. Paris: Vrin, 1994. p. 7-10.

FOUCAULT, M. Michel Foucault: Introduction à l'Anthropologie de Kant (Genèse et structure d'Anthropologie de Kant). Ed. Frédéric Gros, Daniel Defert e François Ewald. Paris: Vrin: 2008.

FOUCAULT, M. Gênese e estrutura da Antropologia de Kant. Trad. Salma Tannus Muchail e Márcio Alves da Fonseca. São Paulo: Loyola, 2011.

FOUCAUlT, M. Naissance de la clinique. 5. ed. Paris: Quadriage/Presses Universitaires de France, 1997.

FOUCAULT, M. As palavras e as coisas. Trad. Salma Tannus Muchail. 8. ed. São Paulo: Martins Fontes, 2000.

FOUCAULT, M. L'archéologie du savoir. Paris: Gallimard, 1969.

FOUCAULT, M. Histoire de la sexualité, 2: L'usage des plaisirs. Paris: Gallimard, 1984. 
FOUCAULT, M. Histoire de la sexualité, 4: Les aveux de la chair. Paris: Gallimard, 2018.

FOUCAULT, M. Du gouvernement des vivants: cours au Collège de France (1980). Dir. François Ewald e Alessandro Fontana, ed. Michel Sennellart. Paris: Gallimard, 2012.

FOUCAULT, M. Dits et écrits, II. Ed. François Ewald, Daniel Defert, colab. Jacques Lagrange. Paris: Quarto/Gallimard, 2001.

GROS, F. Situation du cours. In: FOUCAULT, M. Le courage de la vérité. Paris: Gallimard, 2009. p. 314-328.

JAMES, W. Segunda Conferência: o que significa pragmatismo? In: Os pensadores, XL. Trad. Pablo Rubén Mariconda. São Paulo: Abril Cultural, 1974. p. 11-37.

KANT, I. Anthropologie du point de vue pragmatique. Trad. Michel Foucault. 3. ed. Paris: Vrin, 1994.

LE BLANC, G. La pensée Foucault. Paris: Ellipses, 2006.

NEGRI, A. Um novo Foucault: uma entrevista. In: NEGRI, A. Quando e como eu li Foucault. Org. Mario A. Marino. São Paulo: N-1 edições, 2016. p. 15-16.

RAJCHMAN, J. Foucault pragmático. In: PORTOCARRERO, V.; CASTELO BRANCO, G. (Org.). Retratos de Foucault. Rio de Janeiro: Nau, 2000. p. 68-87.

Recebido: 17/09/2018

Received: 09/17/2018

Aprovado: 09/10/2018

Approved: 10/09/2018 